Accepted ver.

Central European journal of operations research. - ISSN 1435-246X. - Vol. 19, iss. 3 (2011):

267-284 doi: 10.1007/s10100-011-0191-x

\title{
METHODS BASED ON DATA ENVELOPMENT \\ ANALYSIS FOR DERIVING GROUP \\ PRIORITIES IN ANALYTIC HIERARCHY \\ PROCESS
}

\author{
Petra Grošelj, Špela Pezdevšek Malovrh, Lidija Zadnik Stirn \\ University of Ljubljana, Biotechnical Faculty \\ Jamnikarjeva 101, 1000 Ljubljana, Slovenia \\ e-mail: petra.groselj@bf.uni-lj.si, spela.pezdevsek.malovrh@bf.uni-lj.si, lidija.zadnik@bf.uni-lj.si
}

\begin{abstract}
In recent years, group decision making has become one of the important issues in multiple criteria decision making, and analytic hierarchy process (AHP) is considered an appropriate method when dealing with this kind of problems. Many different approaches for attaining a group valuation in AHP have been developed. The applications most commonly employ the weighted geometric mean method. In the paper, we focus on the group AHP methods, which are based on the data envelopment analysis (DEA). First we discuss two methods for deriving a group priority vector: Wang and Chin's DEA group method and Hosseinian et al.'s DEA-WDGD. Further, we propose a new WGMDEA method and compare all three methods with the WGMM on theoretical examples and on a real case study. The objective of the case study is to examine the current state of forest owners' cooperatives. An analysis of the influence of forest owners' cooperatives on private forest management in Slovenia was put forward. The A'WOT analysis, which is a combined method of AHP and SWOT analysis, an approach for identifying the strengths, weaknesses, opportunities and threats of the object under consideration, was performed.
\end{abstract}

Key words: multiple criteria decision making; group decision making; analytic hierarchy process; data envelopment analysis, forest owners' cooperatives, A’WOT analysis

\section{INTRODUCTION}


Group decision making is more complex than the decision making with only one decision maker. Further, it is more realistic, as more people and/or interest groups are included in the decision making process. Group decision making has been discussed in different scientific fields, and is handled by two fundamental methods: social choice theory for unstructured problems and multiple criteria decision making for structured decision making problems (Srdjevic 2007). In the paper we focus on multi criteria decision making, where analytic hierarchy process (AHP) (Saaty 1980) is one of the most suitable and best estimated group methods (Peniwati 2007).

The basic methods for attaining a group valuation in AHP are a consensus between the decision makers, compromise or voting and several aggregating techniques. Aggregating methods can be divided into two fundamental groups (Forman and Peniwati 1998): the aggregation of individual priorities (AIP) and the aggregation of individual judgments (AIJ). The AIP is appropriate when the group consists of separate individuals with different or even conflicting interests. In this case the weighted arithmetic mean method (WAMM) (Ramanathan and Ganesh 1994) or the weighted geometric mean method (WGMM) (Forman and Peniwati 1998) is supposed to be used. The AIJ is suitable when the group is homogeneous, which is hard to achieve in a larger group (Saaty and Vargas 2007). One of the solutions for this problem is a formation of clusters of subgroups (Zahir 1999). In AIJ the function for synthesizing the judgments has to satisfy the following axiomatic conditions: separability, unamity, homogenity and power conditions (Saaty 2001). Reciprocity is a special case of power conditions. The only method that satisfies these axiomatic conditions is the geometric mean method (GMM) (Aczel and Saaty 1983). If the importance of the individual's opinions is not equal for all decision makers, the separability condition is replaced by the weighted separability and GMM is then replaced by WGMM (Aczel and Alsina 1986).

To date there have been many others group AHP methods developed, which are based on different approaches: the aggregation of individual preference structures (Escobar and Moreno-Jimenez 2007), the core of consistency (Moreno-Jimenez et al. 2008), the group method using the concept of Taguchi's loss function (Cho and Cho, 2008), goal programming (Bryson and Joseph, 1999), fuzzy preference programming (Mikhailov, 2004), the group method, using the minimization of 
weighted deviation measure (Sun and Greenberg, 2006). There are also some group AHP methods which are based on the data envelopment analysis (DEA) (Charnes et al. 1978). Wang and Chin (2009) presented DEA methodology for the group decision making, which is based on DEA method prioritization procedure (DEAW\&C), while Hosseinian et al. (2009) proposed the DEA-WDGD method. Most of these approaches have not been used in any applications yet and have not been compared to other group AHP methods.

The aim of the paper is to put forward a new weighted geometric mean DEA method (WGMDEA), and to generate a comparison of the DEA based group methods, DEAW\&C, DEA-WDGD and WGMDEA with the WGMM.

In the paper, first the foundations of AHP are given. Then the WGMM, the group AHP method, as used in many applications (Korpela and Tuominen 1997; Liberatore and Nydick 1997; Duke and Aull-Hyde 2002; Ananda and Herath 2008 and others) is presented. The basis of the DEA is provided next, followed by its adaptation for AHP, i.e., the DEA method for deriving the priority vector. Further, we discuss two methods for deriving a group priority vector which are based on the DEA: DEAW\&C and DEA-WDGD method. We show that these both group methods violate the reciprocal property which is required in the AHP model. In the DEA-WDGD we show that there exists a closed form solution. Further, we propose a new WGMDEA method and compare all three methods (DEAW\&C, DEA-WDGD and WGMDEA) with the classic WGMM. The comparison is made on two theoretical examples and on a real case study of cooperatives.

\section{THE FOUNDATIONS OF AHP}

The structure of AHP is hierarchical. A fundamental scale of the AHP (Saaty 1980) from 1 to 9 is used for pairwise comparisons which are the basis of AHP. A reciprocal value is assigned to the inverse comparison, i. e. $a_{i j}=1 / a_{j i}$. The comparisons are gathered in a comparison matrix $A(1)$. 


$$
A=\left[\begin{array}{cccc}
1 & a_{12} & \cdots & a_{1 n} \\
\frac{1}{a_{12}} & 1 & \cdots & a_{2 n} \\
\vdots & \vdots & \ddots & \vdots \\
\frac{1}{a_{1 n}} & \frac{1}{a_{2 n}} & \cdots & 1
\end{array}\right]
$$

For deriving priorities, Saaty (1980) presented the eigenvector method (EV), where the local priority vector $w=\left(w_{1}, \ldots, w_{n}\right)$ is obtained by solving the equation $A w=\lambda_{\max } w$, where $\lambda_{\max }$ is the largest eigenvalue of the matrix $A$.

The comparison matrix $A$ is consistent if its entries satisfy: $a_{i j} a_{j k}=a_{i k}, i, j$, $k=1, \ldots, n$. Consistency ratio (2) measures the inconsistency among the pairwise comparisons:

$$
C R=\frac{C I}{R I},
$$

where $C I=\frac{\lambda_{\max }-n}{n-1}$ is the consistency index, $n$ is the order of matrix $A$ and $R I$ is the average random consistency index. If $C R<0.1$, the inconsistency is acceptable.

\subsection{THE WGMM FOR DERIVING THE GROUP PRIORITY VECTOR}

In the group decision making there are $m$ decision makers with $n \times n$ comparison matrices $A^{(k)}=\left(a_{i j}{ }^{(k)}\right)_{n \times n}, k=1, \ldots, m$. Their opinions are not necessarily equally important. Some decision makers can have higher formal authority, can be greater experts in the considered field or have bigger influence. Such decision makers can have higher weights assigned by the leader of the decision making process, which means that their judgments or priorities will have bigger influence on the group judgments or priorities. The relative importance weight of $k$-th decision maker's opinion is denoted by $\alpha_{k}$, for $k=1, \ldots, m$, with $\alpha_{k}>0$ and $\sum_{k=1}^{m} \alpha_{k}=1$. In the most applied group AHP methods, i.e. in the WGMM, the group opinion is presented by the weighted geometric mean complex judgment matrix $A^{W G M}=\left(a_{i j}{ }^{W G M}\right)_{n \times n}$, 
where $a_{i j}{ }^{W G M}=\prod_{k=1}^{m}\left(a_{i j}{ }^{(k)}\right)^{\alpha_{k}}$. The group priority vector is derived from $A^{W G M}$ by the EV.

\section{THE FOUNDATIONS OF DEA}

DEA is a method for measuring the efficiency of decision making units (DMUs), which convert multiple inputs into multiple outputs (Table 1). It is based on linear programming (LP). The goal of DEA is to maximize the efficiency of DMUs, which is defined as the ratio of the weighted sum of outputs to the weighted sum of inputs. Charnes et al. (1978) presented the model, which they transformed to the LP model (3):

$$
\begin{aligned}
\max w_{0}= & \sum_{r=1}^{s} y_{0 r} v_{r}, \\
\text { subject to } & \sum_{r=1}^{s} y_{j r} v_{r}-\sum_{i=1}^{m} x_{j i} u_{i} \leq 0, j=1, \ldots, n \\
& \sum_{i=1}^{m} x_{0 i} u_{i}=1 \\
& v_{r} \geq 0, \quad r=1, \ldots, s \\
& u_{i} \geq 0, \quad i=1, \ldots, m,
\end{aligned}
$$

where $x_{j i}$ is the input values and $y_{j r}$ is the output values of $j$ th DMU, $u_{i}$ is the weight assigned to the input $i$ and $v_{r}$ is the weight assigned to the output $r$.

\begin{tabular}{|c|c|c|c|c|c|c|}
\hline & input 1 & $\ldots$ & input m & output 1 & $\ldots$ & output s \\
\hline DMU 1 & $x_{11}$ & $\ldots$ & $x_{1 m}$ & $y_{11}$ & $\ldots$ & $y_{1 s}$ \\
\hline$\vdots$ & $\vdots$ & $\ldots$ & $\vdots$ & $\vdots$ & $\ldots$ & $\vdots$ \\
\hline DMU n & $x_{1 n}$ & $\ldots$ & $x_{n m}$ & $y_{n 1}$ & $\ldots$ & $y_{n s}$ \\
\hline
\end{tabular}

Table 1: Inputs and outputs regarding the DMUs in DEA (Ramanathan, 2006)

\subsection{DEA METHOD FOR DERIVING THE PRIORITY VECTOR}


Ramanathan (2006) was the first to develop a method based on DEA, the DEAHP method, for deriving weights from a comparison matrix. Numerical examples showed that this method has some drawbacks (Wang and Chin 2009). Wang and Chin (2009) proposed a new DEA method (4) to defeat these problems.

Let each row of the comparison matrix $A$ be a DMU, each column an output and a dummy input of value one for all the DMUs (Table 2).

\begin{tabular}{|c|c|c|c|c|}
\hline criterion (or alternative) & $\begin{array}{c}\text { Dummy } \\
\text { input }\end{array}$ & output 1 & $\ldots$ & output $n$ \\
\hline 1 & 1 & $a_{11}$ & $\ldots$ & $a_{1 n}$ \\
\hline$\vdots$ & 1 & $\vdots$ & $\ldots$ & $\vdots$ \\
\hline $\mathrm{n}$ & 1 & $a_{n 1}$ & $\ldots$ & $a_{n n}$ \\
\hline
\end{tabular}

Table 2: DEA view of comparison matrix in new DEA method

They defined the relative score $w_{i}=\frac{s_{i}}{\sum_{k=1}^{n} s_{k}}, s_{i}=\sum_{j=1}^{n} a_{i j} v_{j}, i=1, \ldots, n$ as the local priority of the $i$ th criterion and considered the inequality $s_{i}=\sum_{j=1}^{n} a_{i j} v_{j} \geq n v_{i}$, $i=1, \ldots, n$ which is known from EV method. After some transformations Wang and Chin (2009) obtained the LP model (4):

$$
\begin{aligned}
& \max w_{0}=\sum_{j=1}^{n} a_{0 j} x_{j}, \\
& \text { subject to: } \sum_{j=1}^{n}\left(\sum_{i=1}^{n} a_{i j}\right) x_{j}=1, \\
& \qquad \sum_{j=1}^{n} a_{i j} x_{j} \geq n x_{i}, i=1, \ldots, n, \\
& x_{j} \geq 0, j=1, \ldots, n .
\end{aligned}
$$

The local priority for each criterion (or alternative) can be derived by solving the LP model (4) for all $w_{i}, i=1, \ldots, n$.

Wang and Chin (2009) proved that the LP model (4) produces true local priorities for a perfectly consistent comparison matrix. 


\section{GROUP AHP METHODS BASED ON DEA}

Here we present three DEA based methods for deriving priority vector in group problems. The first and the second methods are taken from literature and have some drawbacks while the third is our own generated model.

\subsection{DEAW\&C method}

Wang and Chin (2009) extended the new DEA method to the group decision DEAW\&C LP model (5):

$$
\begin{aligned}
\max w_{0}= & \sum_{j=1}^{n}\left(\sum_{k=1}^{m} \alpha_{k} a_{0 j}{ }^{(k)}\right) x_{j}, \\
\text { subject to: } & \sum_{j=1}^{n}\left(\sum_{k=1}^{m} \sum_{i=1}^{n} \alpha_{k} a_{i j}{ }^{(k)}\right) x_{j}=1, \\
& \sum_{j=1}^{n}\left(\sum_{k=1}^{m} \alpha_{k} a_{i j}{ }^{(k)}\right) x_{j} \geq n x_{i}, i=1, \ldots, n, \\
& x_{j} \geq 0, j=1, \ldots, n .
\end{aligned}
$$

The DEA concept of the group model is similar to the DEA concept in one decision maker's case (Table 2), only the output values are the weighted arithmetic means of judgments (Table 3).

\begin{tabular}{|c|c|c|c|c|}
\hline criterion (or alternative) & dummy input & output 1 & $\ldots$ & output n \\
\hline 1 & 1 & $\sum_{k=1}^{m} \alpha_{k} a_{11}{ }^{\left({ }^{k}\right)}$ & $\ldots$ & $\sum_{k=1}^{m} \alpha_{k} a_{1 n}{ }^{(k)}$ \\
\hline$\vdots$ & 1 & $\vdots$ & $\ldots$ & $\vdots$ \\
\hline $\mathrm{n}$ & 1 & $\sum_{k=1}^{m} \alpha_{k} a_{1 n}{ }^{\left({ }^{k}\right)}$ & $\ldots$ & $\sum_{k=1}^{m} \alpha_{k} a_{n n}{ }^{\left({ }^{k}\right)}$ \\
\hline
\end{tabular}

Table 3: DEA view of comparison matrices in the DEAW\&C method

The question is how good this group model actually is. Since group decision making is a generalization of one decision maker's case, the group model should be applicable to the one decision maker case (Sun and Greenberg, 2006). Let us 
denote the weighted arithmetic mean of comparison matrices $A^{(k)}, k=1, \ldots, m$, by $B=\left(b_{i j}\right)_{n \times n}, \quad b_{i j}=\sum_{k=1}^{m} \alpha_{k} a_{i j}{ }^{(k)}$. Since $\sum_{k=1}^{m} \sum_{i=1}^{n} \alpha_{k} a_{i j}{ }^{(k)}=\sum_{i=1}^{n} \sum_{k=1}^{m} \alpha_{k} a_{i j}{ }^{(k)}$, the mode

can be written as:

$$
\begin{aligned}
& \max w_{0}=\sum_{j=1}^{n} b_{0 j} x_{j}, \\
& \text { subject to: } \sum_{j=1}^{n}\left(\sum_{i=1}^{n} b_{i j}\right) x_{j}=1, \\
& \qquad \sum_{j=1}^{n} b_{i j} x_{j} \geq n x_{i}, i=1, \ldots, n, \\
& x_{j} \geq 0, j=1, \ldots, n .
\end{aligned}
$$

Model (6) is equal to the LP model (4) for one decision maker whose comparison matrix is the weighted arithmetic mean of comparison matrices of $m$ decision makers. Since generally $\frac{1}{\sum_{k=1}^{m} \alpha_{k} a_{i j}{ }^{(k)}} \neq \sum_{k=1}^{m} \alpha_{k} \frac{1}{a_{i j}{ }^{(k)}}$, the weighted arithmetic mean of comparison matrices violates the reciprocal property which is required in the AHP model. The lack of reciprocal property means that model (5) violates one of the most important properties for an AHP model.

\subsection{DEA - WDGD method}

Hosseinian et al. (2009) proposed a method for deriving group priorities which is also based on the DEA and which enables simpler derivation of weights than the DEAW\&C method. In the DEA-WDGD model there is only one LP to solve. In the DEA-WDGD method each criterion (or alternative) is viewed as a DMU and each decision maker as an output (Table 4).

\begin{tabular}{|c|c|c|c|}
\hline criterion (or alternative) & $\mathrm{DM}_{1}$ & $\ldots$ & $\mathrm{DM}_{\mathrm{m}}$ \\
\hline 1 & $\sum_{j=1}^{n} a_{1 j}{ }^{(1)}$ & $\ldots$ & $\sum_{j=1}^{n} a_{1 j}{ }^{(m)}$ \\
\hline
\end{tabular}




\begin{tabular}{|c|c|c|c|}
\hline$\vdots$ & $\vdots$ & $\ldots$ & $\vdots$ \\
\hline $\mathrm{n}$ & $\sum_{j=1}^{n} a_{n j}{ }^{(1)}$ & $\ldots$ & $\sum_{j=1}^{n} a_{n j}{ }^{(m)}$ \\
\hline
\end{tabular}

Table 4: DEA view of comparison matrices in the DEA-WDGD method (Hosseinian et al., 2009)

The group priorities are the solution of the LP model (7):

$$
\begin{array}{ll}
\max & \sum_{i=1}^{n} w_{i}, \\
\text { subject to: } & \sum_{k=1}^{m}\left(\sum_{j=1}^{n} a_{i j}{ }^{(k)}\right) v_{k}-w_{i}=0, i=1, \ldots, n, \\
& \sum_{i=1}^{n} w_{i} \leq 1, \\
& \alpha_{k} v_{k+1}-\alpha_{k+1} v_{k}=0, k=1, \ldots, m-1, \\
& w_{i} \geq 0, i=1, \ldots, n, \\
& v_{k} \geq 0, k=1, \ldots, m .
\end{array}
$$

We ascertained-propose Theorem 1 which presents a closed form solution for model (7).

aclosed form solution of the LP model (7), which is given in Theorem 1.

Theorem 1: LP model (7) has the closed form solution (8):

$$
\begin{aligned}
& v_{k}=\frac{\alpha_{k}}{\sum_{i=1}^{n} \sum_{k=1}^{m} \sum_{j=1}^{n} a_{i j}{ }^{(k)} \alpha_{k}}, k=1, \ldots, n \text { and } \\
& w_{i}=\frac{\sum_{k=1}^{m} \sum_{j=1}^{n} a_{i j}{ }^{\left({ }^{k}\right)} \alpha_{k}}{\sum_{i=1}^{n} \sum_{k=1}^{m} \sum_{j=1}^{n} a_{i j}{ }^{(k)} \alpha_{k}}, i=1, \ldots, n .
\end{aligned}
$$

Proof: All the constraints from model (7) are fulfilled:

$$
v_{k}=\frac{\alpha_{k}}{\sum_{i=1}^{n} \sum_{k=1}^{m} \sum_{j=1}^{n} a_{i j}{ }^{(k)} \alpha_{k}} \geq 0 \text { for } k=1, \ldots, n
$$




$$
\begin{gathered}
w_{i}=\frac{\sum_{k=1}^{m} \sum_{j=1}^{n} a_{i j}{ }^{\left({ }^{k}\right)} \alpha_{k}}{\sum_{i=1}^{n} \sum_{k=1}^{m} \sum_{j=1}^{n} a_{i j}{ }^{(k)} \alpha_{k}} \geq 0 \text { for } i=1, \ldots, n . \\
\sum_{k=1}^{m}\left(\sum_{j=1}^{n} a_{i j}{ }^{(k)}\right) v_{k}-w_{i}=\sum_{k=1}^{m}\left(\sum_{j=1}^{n} a_{i j}{ }^{(k)}\right) \frac{\alpha_{k}}{\sum_{i=1}^{n} \sum_{k=1}^{m} \sum_{j=1}^{n} a_{i j}{ }^{(k)} \alpha_{k}}-\frac{\sum_{k=1}^{m} \sum_{j=1}^{n} a_{i j}{ }^{\left({ }^{k}\right)} \alpha_{k} \sum_{k=1}^{n} \sum_{j=1} a_{i j}{ }^{(k)} \alpha_{k}}{i=1, \ldots, n .}=0 \text { for } \\
\sum_{i=1}^{n} w_{i}=\sum_{i=1}^{n} \frac{\sum_{k=1}^{m} \sum_{j=1}^{n} \sum_{i=1}^{m} \sum_{k=1}^{m} \sum_{j=1}^{n} a_{i j}{ }^{(k)} \alpha_{k}}{{ }^{(k)} \alpha_{k}}=1 . \\
\alpha_{k} v_{k+1}-\alpha_{k+1} v_{k}=\alpha_{k} \frac{\alpha_{k+1}}{\sum_{i=1}^{n} \sum_{k=1}^{m} \sum_{j=1}^{n} a_{i j}{ }^{(k)} \alpha_{k}}-\alpha_{k+1} \frac{\alpha_{k}}{\sum_{i=1}^{n} \sum_{k=1}^{m} \sum_{j=1}^{n} a_{i j}{ }^{(k)} \alpha_{k}}=0 \text { for } k=1, \ldots, m-1 .
\end{gathered}
$$

Since $\sum_{i=1}^{n} w_{i}=1$, the maximum of the objective function $\sum_{i=1}^{n} w_{i}$ is attained and the proof is completed.

How is this model conceivable for one decision maker? If $m=1$ and $\alpha_{1}=1$ in the solution (8) we obtain:

$$
w_{i}=\frac{\sum_{j=1}^{n} a_{i j}{ }^{(1)}}{\sum_{i=1}^{n} \sum_{j=1}^{n} a_{i j}{ }^{(1)}}, i=1, \ldots, n,
$$

that is a Simple column sum method (SCS) (Zahedi 1986) for one decision maker. In the SCS, columns are added, which are usually not proportional. So it is not expected for the SCS to work out well in comparison to the other methods for deriving priorities in one decision maker case (Choo and Wedley, 2004).

If we denote the weighted arithmetic mean of comparison matrices $A^{(k)}$, $k=1, \ldots, m$, by $B=\left(b_{i j}\right)_{n \times n}, b_{i j}=\sum_{k=1}^{m} \alpha_{k} a_{i j}{ }^{(k)}$ and since 
$w_{i}=\frac{\sum_{k=1}^{m} \sum_{j=1}^{n} a_{i j}{ }^{\left({ }^{k)}\right.} \alpha_{k}}{\sum_{i=1}^{n} \sum_{k=1}^{m} \sum_{j=1}^{n} a_{i j}{ }^{(k)} \alpha_{k}}=\frac{\sum_{j=1}^{n} \sum_{k=1}^{m} a_{i j}{ }^{\left({ }^{k}\right)} \alpha_{k}}{\sum_{i=1}^{n} \sum_{j=1}^{n} \sum_{k=1}^{m} a_{i j}{ }^{(k)} \alpha_{k}}=\frac{\sum_{j=1}^{n} b_{i j}}{\sum_{i=1}^{n} \sum_{j=1}^{n} b_{i j}}$, the solution of the DEAWDGD method is the same as the solution of the SCS method for one decision maker whose comparison matrix is the weighted arithmetic mean of comparison matrices of $m$ decision makers, and which violates the reciprocal property which is required in the AHP model.

\subsection{WGMDEA model}

Since both models (the DEAW\&C and the DEA-WDGD) violate the reciprocal property we suggest a new model (10), assigned as the weighted geometric mean DEA model (WGMDEA). DMUs in model (10) are the rows of the weighted geometric mean complex judgment matrix $A^{W G M}$, which implies one DMU for each criterion (or alternative). As in new DEA method only a dummy input of value one for all DMUs is used, the $n$ outputs belong to the columns of $A^{W G M}$, which signifies that the values of outputs are equal to the weighted geometric means of the judgments (Table 5).

\begin{tabular}{|c|c|c|c|c|}
\hline criterion (or alternative) & dummy input & output 1 & $\ldots$ & output n \\
\hline 1 & 1 & $\sum_{k=1}^{m} \alpha_{k} a_{11}{ }^{(k)}$ & $\ldots$ & $\sum_{k=1}^{m} \alpha_{k} a_{1 n}{ }^{(k)}$ \\
\hline$\vdots$ & 1 & $\vdots$ & $\ldots$ & $\vdots$ \\
\hline $\mathrm{n}$ & 1 & $\sum_{k=1}^{m} \alpha_{k} a_{1 n}{ }^{(k)}$ & $\ldots$ & $\sum_{k=1}^{m} \alpha_{k} a_{n n}{ }^{(k)}$ \\
\hline
\end{tabular}

Table 5: DEA view in WGMDEA method

The WGMDEA model is an LP model for deriving group priorities (10):

$$
\begin{aligned}
\max w_{0}= & \sum_{j=1}^{n}\left(\prod_{k=1}^{m}\left(a_{0 j}{ }^{(k)}\right)^{\alpha_{k}}\right) x_{j}, \\
\text { subject to: } & \sum_{j=1}^{n}\left(\sum_{i=1}^{n} \prod_{k=1}^{m}\left(a_{i j}{ }^{(k)}\right)^{\alpha_{k}}\right) x_{j}=1, \\
& \sum_{j=1}^{n}\left(\prod_{k=1}^{m}\left(a_{i j}{ }^{(k)}\right)^{\alpha_{k}}\right) x_{j} \geq n x_{i}, i=1, \ldots, n,
\end{aligned}
$$




$$
x_{j} \geq 0, j=1, \ldots, n
$$

It is similar to the DEAW\&C LP model (5) but it uses the weighted geometric mean that keeps the reciprocal property instead of the weighted arithmetic mean. It is a generalization of the new DEA method (4) for one decision maker. If we denote the weighted geometric mean of comparison matrices $A^{(k)}, k=1, \ldots, m$, by $C=\left(c_{i j}\right)_{n \times n}, c_{i j}=\prod_{k=1}^{m}\left(a_{i j}{ }^{(k)}\right)^{\alpha_{k}}$, model (10) can be written:

$$
\begin{aligned}
& \max w_{0}=\sum_{j=1}^{n} c_{0 j} x_{j}, \\
& \text { subject to: } \sum_{j=1}^{n}\left(\sum_{i=1}^{n} c_{i j}\right) x_{j}=1, \\
& \sum_{j=1}^{n} c_{i j} x_{j} \geq n x_{i}, i=1, \ldots, n, \\
& x_{j} \geq 0, j=1, \ldots, n .
\end{aligned}
$$

Model (11) is equal to the LP model (4) for one decision maker whose comparison matrix is the weighted geometric mean of comparison matrices of $m$ decision makers.

\section{NUMERICAL EXAMPLES}

In two theoretical examples and in a case study we compare and evaluate the four presented group AHP methods (the WGMM, the WGMDEA, the DEAW\&C and the DEA-WDGD).

\subsection{Example 1}

The following example shows that the results of the DEA-WDGD method can be illogical. 
Let $A=\left[\begin{array}{cccc}1 & 1 & 2 & 5 \\ 1 & 1 & 2 & 5 \\ \frac{1}{2} & \frac{1}{2} & 1 & 7 \\ \frac{1}{5} & \frac{1}{5} & \frac{1}{7} & 1\end{array}\right], B=\left[\begin{array}{cccc}1 & 1 & 2 & 4 \\ 1 & 1 & 2 & 4 \\ \frac{1}{2} & \frac{1}{2} & 1 & 6 \\ \frac{1}{4} & \frac{1}{4} & \frac{1}{6} & 1\end{array}\right]$ and $C=\left[\begin{array}{cccc}1 & 1 & 2 & 6 \\ 1 & 1 & 2 & 6 \\ \frac{1}{2} & \frac{1}{2} & 1 & 8 \\ \frac{1}{6} & \frac{1}{6} & \frac{1}{8} & 1\end{array}\right]$ be

the comparison matrices of three decision makers with equal relative importance weights of decision makers' opinions ( $\left.\alpha_{1}=\alpha_{2}=\alpha_{3}=\frac{1}{3}\right)$. All three matrices are of acceptable consistency, since the consistency ratios are $C R_{A}=0.051$, $C R_{B}=0.058$ and $C R_{C}=0.046$, respectively. In this example all three decision makers estimated that the first and the second alternative are of equal importance and are better than the third alternative. We calculated the group priority vectors by the WGMM, the WGMDEA method, proposed as a new method in this paper and given by (10), the DEAW\&C, given by (5) and the DEA-WDGD method, given by (7). The results are presented in Table 6 .

\begin{tabular}{|c|cc|cc|cc|cc|}
\hline & WGMM & Rank & WGMDEA & Rank & DEAW\&C & Rank & DEA-WDGD & Rank \\
\hline $\mathrm{w}_{1}$ & 0.3529 & $1-2$ & 0.3524 & $1-2$ & 0.3520 & $1-2$ & 0.3152 & $1-3$ \\
$\mathrm{w}_{2}$ & 0.3529 & $1-2$ & 0.3524 & $1-2$ & 0.3520 & $1-2$ & 0.3152 & $1-3$ \\
$\mathrm{w}_{3}$ & 0.2377 & 3 & 0.2382 & 3 & 0.2385 & 3 & 0.3152 & $1-3$ \\
$\mathrm{w}_{4}$ & 0.0565 & 4 & 0.0571 & 4 & 0.0575 & 4 & 0.0544 & 4 \\
\hline
\end{tabular}

Table 6: Priority vector obtained by group methods for Example 1

The results show that by using the WGMM, WGMDEA and DEAW\&C methods the group priorities for the first and second alternative are equal and higher than the priority of the third alternative, while by the DEA-WDGD method the priorities of the first three alternatives are the same, which is illogical.

\subsection{Example 2}

For the evaluation of the DEAW\&C and the DEA-WDGD methods Hosseinian et al. (2009) applied the fitting performance index (FP) (12):

$$
F P=\sqrt{\frac{1}{n^{2}} \sum_{i=1}^{n} \sum_{j=1}^{n}\left(a_{i j}{ }^{(W G M)}-\frac{w_{i}}{w_{j}}\right)^{2}}
$$

FP measures the average sum of distances between the ratios of priorities and the elements of $A^{W G M}$. Lower FP indicates better performance of the method. We 
employ the numerical example which Hosseinian et al. (2009) borrowed from Wang and Chin (2009). We use FP index to show on their examples that the new method WGMDEA, which is presented in this paper, has a better performance.

Let

$$
A^{(1)}=\left[\begin{array}{ccccc}
1 & 1 & 3 & 4 & 1 \\
1 & 1 & 1 & \frac{1}{2} & \frac{1}{3} \\
\frac{1}{3} & 1 & 1 & \frac{1}{2} & \frac{1}{2} \\
\frac{1}{4} & 2 & 2 & 1 & \frac{1}{2} \\
1 & 3 & 2 & 2 & 1
\end{array}\right], \quad A^{(2)}=\left[\begin{array}{ccccc}
1 & 8 & 1 & 2 & 2 \\
\frac{1}{8} & 1 & \frac{1}{8} & \frac{1}{3} & \frac{1}{5} \\
1 & 8 & 1 & 2 & 2 \\
\frac{1}{2} & 3 & \frac{1}{2} & 1 & 1 \\
\frac{1}{2} & 5 & \frac{1}{2} & 1 & 1
\end{array}\right],
$$

$$
A^{(3)}=\left[\begin{array}{ccccc}
1 & 8 & 1 & 1 & 1 \\
\frac{1}{8} & 1 & \frac{1}{8} & \frac{1}{5} & \frac{1}{8} \\
1 & 8 & 1 & 2 & 1 \\
1 & 5 & \frac{1}{2} & 1 & 1 \\
1 & 8 & 1 & 1 & 1
\end{array}\right] \text { and } A^{(4)}=\left[\begin{array}{ccccc}
1 & 2 & 1 & 1 & 1 \\
\frac{1}{2} & 1 & \frac{1}{2} & 1 & 1 \\
1 & 2 & 1 & \frac{1}{2} & 1 \\
1 & 1 & 2 & 1 & 1 \\
1 & 1 & 1 & 1 & 1
\end{array}\right] \text { be the }
$$

comparison matrices of four decision makers and $\alpha_{k}, \mathrm{k}=1, \ldots, 4$, relative importance weights of decision makers' opinions. The consistency ratios of comparison matrices are $C R_{A}=0.088, C R_{B}=0.005, C R_{C}=0.013$ and $C R_{D}=0.040$ respectively, which implies that all comparison matrices are of acceptable consistency. The group priority vectors for four methods and different relative importance weights of decision maker opinions are presented in Table 7. The FP indexes for all methods are calculated.

\begin{tabular}{|cl|ccccc|c|}
\hline$\alpha_{1}, \alpha_{2}, \alpha_{3}, \alpha_{4}$ & Method & $\mathrm{w}_{1}$ & $\mathrm{w}_{2}$ & $\mathrm{w}_{3}$ & $\mathrm{w}_{4}$ & $\mathrm{w}_{5}$ & $\mathrm{FP}$ \\
\hline & WGMM & 0.3108 & 0.0793 & 0.1881 & 0.1724 & 0.2494 & 0.3394 \\
$0.5,0.3,0.15$, & WGMDEA & 0.3112 & 0.0792 & 0.1881 & 0.1724 & 0.2491 & 0.3403 \\
0.05 & DEA-WDGD & 0.3015 & 0.0771 & 0.2159 & 0.1668 & 0.2388 & 0.3541 \\
& DEAW\&C & 0.3092 & 0.0906 & 0.2054 & 0.1662 & 0.2287 & 0.3780 \\
\hline & WGMM & 0.2958 & 0.0913 & 0.1772 & 0.1812 & 0.2544 & 0.2743 \\
$0.5,0.167$, & WGMDEA & 0.2961 & 0.0912 & 0.1773 & 0.1813 & 0.2541 & 0.2749 \\
$0.167,0.167$ & DEA-WDGD & 0.2909 & 0.0885 & 0.1994 & 0.1771 & 0.2440 & 0.2895 \\
& DEAW\&C & 0.2967 & 0.1005 & 0.1912 & 0.1762 & 0.2353 & 0.2991 \\
\hline $0.25,0.25,0.25$, & WGMM & 0.2830 & 0.0749 & 0.2211 & 0.1891 & 0.2320 & 0.1448 \\
0.25 & WGMDEA & 0.2830 & 0.0749 & 0.2211 & 0.1891 & 0.2319 & 0.1448 \\
& DEA-WDGD & 0.2814 & 0.0750 & 0.2400 & 0.1758 & 0.2278 & 0.1442 \\
& DEAW\&C & 0.2803 & 0.0863 & 0.2291 & 0.1845 & 0.2198 & 0.2284 \\
\hline
\end{tabular}

Table 7: Priority vectors and FP indexes obtained by group methods for Example 2

The rankings of the alternatives are equal for all methods and the preferences are similar but the FP indexes differ. When the relative importance weights of decision makers' opinions are not equal, the FP indexes of the WGMM and the WGMDEA are close together, but the FP of the WGMM is slightly lower. The FP 
index of the DEA-WDGD is higher and the FP of the DEAW\&C is the highest. When the relative importance weights of decision makers' opinions are all equal the DEA-WDGD has the lowest FP index although the WGMM and the WGMDEA have FP indexes of the same range. The FP index of the DEAW\&C is the highest again.

\subsection{Case study}

Private forest management is, especially in Slovenia, far from optimal, which is the consequence of different factors. The most important factors are a large number of owners and co-owners and small sizes of forest property which is further fragmented into several separate plots. According to Pezdevšek Malovrh and Krč (2006), successful forest management, based on environmentally friendly, multifunctional and sustainable principles, ensuring public interest as well as the interest of forest owners, can only be implemented through cooperation among owners.

Cooperatives are one of the cooperation forms among private forest owners which have a long tradition and an important role in business cooperation between the owners and the market. Conceptually, cooperatives might enable individual forest owners to participate actively in the wood market. Furthermore cooperatives are a keystone in the dissemination of information and may lead to a successful implementation of forest management.

The objective of this case study is to examine the current state of cooperatives, with a focus on the analysis of influence that forest owners' cooperatives have on private forest management. The data for this analysis were obtained through A'WOT analysis (Kurtilla et.al., 2000). A'WOT is a combined method of AHP and SWOT analysis, an approach for identifying the strengths, weaknesses, opportunities and threats of the analyzed subject. Employees working in the forestry cooperatives were interviewed $(n=4)$. Their opinions were equally important. In the first part of the interview they were asked to express their opinions about the strengths, weaknesses, opportunities and threats of the cooperatives' activities which influence private forest management. Based on 
their opinions the AHP decision tree was built. The AHP decision tree with the results of SWOT analysis is presented in Figure 1.

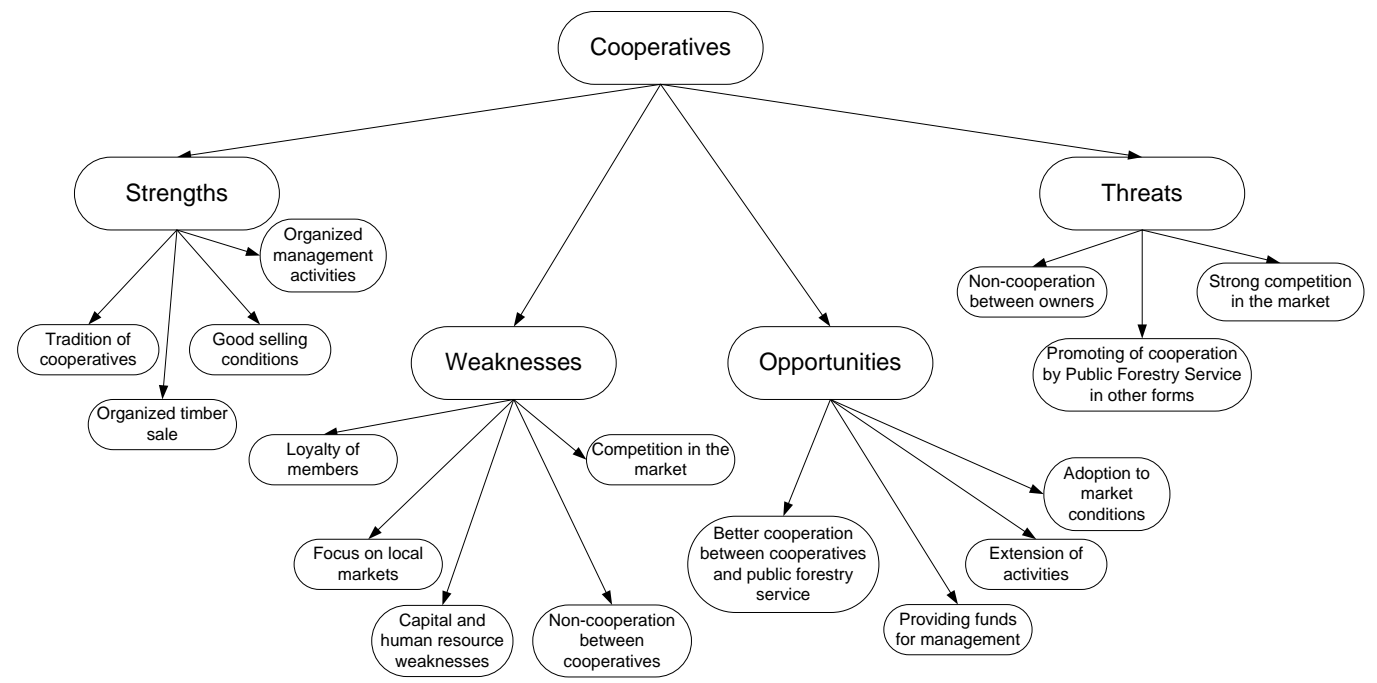

Figure 1: The AHP decision tree with SWOT groups and their factors of cooperatives

In the second part of the interview they were asked to pairwise compare the factors within each of the SWOT groups according to AHP. The consistency ratios of all comparison matrices were calculated and the most inconsistent judgments in comparison matrices were adjusted, so that finally all comparison matrices were of acceptable consistency. The group priority vectors were obtained by group AHP methods presented in the paper, i.e., the WGMM, WGMDEA, DEAW\&C, DEA-WDGD. The FP indexes were calculated for all methods. The results are shown in Table 8, Table 9, Table 10 and Table 11 for strengths, weaknesses, opportunities and threats, respectively. The priorities, derived by the WGMM and DEA-WDGD methods, sum up to one. The sum of priorities, derived by the WGMDEA and DEAW\&C methods, does not equal one, so we normalized them, i.e., we divided each priority by the sum of all priorities and presented them in the non-normalized and in normalized forms.

\begin{tabular}{|c|c|c|c|c|c|c|}
\hline STRENGTHS & WGMM & WGN & $\begin{array}{l}\text { IDEA } \\
\text { Norm. }\end{array}$ & DEA & $\begin{array}{l}\text { N\&C } \\
\text { Norm. }\end{array}$ & DEA-WDGD \\
\hline Tradition of cooperatives & 0.4906 & 0.4915 & 0.4904 & 0.4509 & 0.4135 & 0.4092 \\
\hline Organized timber sale & 0.1531 & 0.1536 & 0.1532 & 0.1851 & 0.1698 & 0.1764 \\
\hline Good selling conditions & 0.1082 & 0.1085 & 0.1083 & 0.1663 & 0.1525 & 0.1416 \\
\hline Organized management activities & 0.2481 & 0.2486 & 0.2481 & 0.2880 & 0.2642 & 0.2728 \\
\hline FP & 0.3218 & \multicolumn{2}{|c|}{0.3212} & \multicolumn{2}{|c|}{0.4653} & 0.4350 \\
\hline
\end{tabular}

Table 8: Group priority vectors and FP indexes obtained by group methods for strengths. The priorities, derived by the WGMM and DEA-WDGD methods are given in normalized form, while the priorities, derived by the WGMDEA and DEAW\&C methods are presented in non-normalized and in normalized forms. 
The results of ranking the strengths were the same regardless of the method used, while the priorities differed between methods. The most valuable strength was the Tradition of cooperatives. Its priority was 0.49 by the WGMM and WGMDEA methods and 0.41 by the DEAW\&C and DEA-WDGD methods. The strength factor Organized timber sale was ranked second. The factor Good selling conditions came third and factor Organized management activities was ranked as the least important strength. The FP index evaluated the WGMDEA as the best method at strengths, closely followed by the WGMM. The DEA-WDGD and DEAW\&C methods were assessed as the third and the least important, respectively.

\begin{tabular}{|l|c|cc|cc|c|}
\hline \multicolumn{1}{|c|}{ WEAKNESSES } & \multirow{2}{*}{ WGMM } & \multicolumn{2}{|c|}{ WGMDEA } & \multicolumn{2}{|c|}{ DEAW\&C } & DEA- \\
& & & Norm. & & Norm. & WDGD \\
\hline Loyalty of members & 0.0905 & 0.0855 & 0.0908 & 0.1168 & 0.1233 & 0.1080 \\
Focus on local markets & 0.3544 & 0.3319 & 0.3522 & 0.2870 & 0.3030 & 0.3079 \\
Capital and human resource & 0.1164 & 0.1088 & 0.1155 & 0.1424 & 0.1503 & 0.1323 \\
weakness & & & & & & \\
Non-cooperation between & 0.2322 & 0.2210 & 0.2345 & 0.1796 & 0.1896 & 0.2054 \\
cooperatives & 0.2065 & 0.1951 & 0.2070 & 0.2213 & 0.2337 & 0.2465 \\
Competition in the market & 0.2045 & \multicolumn{2}{|c|}{0.2114} & \multicolumn{2}{|c|}{0.5875} & 0.4601 \\
\hline FP &
\end{tabular}

Table 9: Group priority vectors and FP indexes obtained by group methods for weaknesses. The priorities, derived by the WGMM and DEA-WDGD methods are given in normalized form, while the priorities, derived by the WGMDEA and DEAW\&C methods are presented in non- normalized and in normalized forms.

The focus on local markets was the most important weakness with all methods, with its priority varying from 0.30 with the DEAW\&C method to 0.35 with the WGMM and WGMDEA methods. The WGMM and WGMDEA placed the weakness Non-cooperation among cooperatives in the second place and the weakness Competition in the market in the third place, while the order of precedence by the other two methods was inverted. Capital and human resource weakness and Loyalty of members were judged as less important weaknesses and were ranked in the last two places with all methods. The WGMM had the lowest FP index, followed by the WGMDEA FP index. The FP indexes of the DEAWDGD and DEAW\&C methods were higher. 


\begin{tabular}{|l|c|cc|cc|c|}
\hline \multicolumn{1}{|c|}{ OPPORTUNITIES } & WGMM & \multicolumn{2}{|c|}{$\begin{array}{r}\text { WGMDEA } \\
\text { Norm. }\end{array}$} & $\begin{array}{r}\text { DEAW\&C } \\
\text { Norm. }\end{array}$ & DEA-WDGD \\
\hline $\begin{array}{l}\text { Better cooperation between } \\
\text { cooperatives and public } \\
\text { forestry service } \\
\text { Providing funds for } \\
\text { management }\end{array}$ & 0.1791 & 0.1800 & 0.1794 & 0.2033 & 0.1753 & 0.1624 \\
$\begin{array}{l}\text { Extension of activities } \\
\text { Adoption to market }\end{array}$ & 0.3539 & 0.3554 & 0.3542 & 0.4227 & 0.3646 & 0.3700 \\
conditions & 0.1739 & 0.2939 & 0.2930 & 0.3251 & 0.2803 & 0.2985 \\
\hline FP & 0.1740 & 0.1734 & 0.2085 & 0.1798 & 0.1692 \\
\hline
\end{tabular}

Table 10: Group priority vectors and FP indexes obtained by group methods for opportunities. The priorities, derived by the WGMM and DEA-WDGD methods are given in normalized form, while the priorities, derived by the WGMDEA and DEAW\&C methods are presented in non- normalized and in normalized form.

The most significant opportunity by all methods was Providing funds for management, followed by the Extension of activities. The WGMM and WGMDEA methods ranked Better cooperation between cooperatives and public forestry service to the third place and Adoption to market conditions as the least important opportunity while the DEAW\&C and DEA-WDGD methods inverted the order of the last two opportunities. The WGMM and WGMDEA were evaluated almost equally by the FP index. The FP indexes of DEAW\&C and DEA-WDGD methods were similar, although a little higher compared to the first two methods.

\begin{tabular}{|l|l|ll|cc|c|}
\hline \multicolumn{1}{|c|}{ THREATS } & \multirow{2}{*}{ WGMM } & \multicolumn{2}{|c|}{ WGMDEA } & \multicolumn{2}{c|}{ DEAW\&C } & DEA- \\
& & \multicolumn{2}{|c|}{ Norm. } & & Norm. & WDGD \\
\hline Non-cooperation between owners & 0.5689 & 0.5689 & 0.5689 & 0.6205 & 0.5367 & 0.6009 \\
Promoting of cooperation by Public & 0.2096 & 0.2097 & 0.2097 & 0.2613 & 0.2260 & 0.1913 \\
Forestry Service in other forms & & & & & & \\
Strong competition in the market & 0.2214 & 0.2214 & 0.2214 & 0.2742 & 0.2372 & 0.2078 \\
\hline FP & 0.0627 & \multicolumn{2}{|c|}{0.0627} & \multicolumn{2}{|c|}{0.1641} & 0.1969 \\
\hline
\end{tabular}

Table 11: Group priority vectors and FP indexes obtained by group methods for threats. The priorities, derived by the WGMM and DEA-WDGD methods are given in normalized form, while the priorities, derived by the WGMDEA and DEAW\&C methods are presented in non- normalized and in normalized forms.

The ranking of threats was the same with all methods, placing Non-cooperation between owners as the most dangerous threat, Promoting of cooperation by Public Forestry Service in other forms as the second and Strong competition in the 
market as the third most dangerous threat. The FP index evaluated the WGMM and WGMDEA equally as the best methods at threats, followed by the DEAW\&C and DEA-WDGD methods, respectively.

The results show that the ranking of factors within all SWOT groups are almost the same for all group methods. The FP index evaluated the WGMM and WGMDEA as the best methods, while the DEAW\&C and DEA-WDGD methods alternated in the third and on the fourth place.

Based on the results of the AHP, the factor with the highest local priority was chosen from each SWOT group to represent it. Strengths were represented by factor Tradition of cooperatives, weaknesses by factor Focus on local markets, opportunities by Providing funds for management and threats by Non-cooperation between owners. These four factors were then pairwise compared as in the second step and their relative priorities were calculated using the AHP group methods.

\begin{tabular}{|c|c|c|c|c|c|c|}
\hline SWOT & WGMM & \multicolumn{2}{|c|}{$\begin{array}{r}\text { WGMDEA } \\
\text { Norm. }\end{array}$} & \multicolumn{2}{|c|}{$\begin{array}{r}\text { DEAW\&C } \\
\text { Norm. }\end{array}$} & DEA-WDGD \\
\hline Strengths & 0.1036 & 0.1043 & 0.1037 & 0.1334 & 0.1257 & 0.1060 \\
\hline Weaknesses & 0.3267 & 0.3299 & 0.3281 & 0.3593 & 0.3386 & 0.3193 \\
\hline Opportunities & 0.2824 & 0.2830 & 0.2816 & 0.2751 & 0.2593 & 0.2792 \\
\hline Threats & 0.2874 & 0.2881 & 0.2866 & 0.2933 & 0.2764 & 0.2954 \\
\hline FP & 0.4230 & \multicolumn{2}{|c|}{0.4264} & \multicolumn{2}{|c|}{0.5429} & 0.4146 \\
\hline
\end{tabular}

Table 12: Group priority vectors and FP indexes obtained by group methods for SWOT factors. The priorities, derived by the WGMM and DEA-WDGD methods are given in normalized form, while the priorities derived by the WGMDEA and DEAW\&C methods are presented in nonnormalized and in normalized form.

The ranking of SWOT groups was the same by all group methods and the priorities were similar. Weaknesses were evaluated as the SWOT group with the highest influence, followed by Threats and Opportunities, respectively. Strengths were judged as the least important SWOT group. FP index evaluated the DEAWDGD as the best method, followed by the WGMM and WGMDEA. The DEAW\&C was positioned in the last place.

Local priorities within and between the SWOT groups were aggregated to global priorities by multiplying the priority of the factor according to the SWOT group and the priority of the SWOT group. The results are presented in Table 13. For the DEAW\&C method the priorities were aggregated in non-normalized form as Wang and Chin (2009) suggest in their presentation of the model. Obtained priorities were then normalized to be comparable to the other results. For aggregation of priorities by the WGMDEA method we also suggest the use of 
normalized priorities. Although we use the 9-point scale for all pairwise comparisons, there may exist problems with disproportionate results which eliminate normalization.

\begin{tabular}{|c|c|c|c|c|c|c|c|c|c|}
\hline & & WGMM & ranks & WGMDE & ranks & DEAW\& & anks & $\begin{array}{l}\text { DEA- } \\
\text { WDGD }\end{array}$ & Ranks \\
\hline & Tradition of cooperatives & 0.0508 & 9 & 0.0519 & 9 & 0.0526 & 9 & 0.0434 & 11 \\
\hline & Organized timber sale & 0.0159 & 15 & 0.0162 & 15 & 0.0216 & 15 & 0.0187 & 15 \\
\hline S & Good selling conditions & 0.0112 & 16 & 0.0115 & 16 & 0.0194 & 16 & 0.0150 & 16 \\
\hline & $\begin{array}{l}\text { Organized management } \\
\text { activities }\end{array}$ & 0.0257 & 14 & 0.0263 & 14 & 0.0336 & 14 & 0.0289 & 14 \\
\hline & Loyalty of members & 0.0296 & 13 & 0.0286 & 13 & 0.0367 & 13 & 0.0345 & 13 \\
\hline & Focus on local markets & 0.1158 & 2 & 0.1109 & 2 & 0.0902 & 3 & 0.0983 & 3 \\
\hline W & $\begin{array}{l}\text { Capital and human } \\
\text { resource weakness }\end{array}$ & 0.0380 & 12 & 0.0364 & 12 & 0.0447 & 12 & 0.0423 & 12 \\
\hline & $\begin{array}{l}\text { Non-cooperation } \\
\text { between cooperatives }\end{array}$ & 0.0759 & 5 & 0.0738 & 5 & 0.0564 & 8 & 0.0656 & 6 \\
\hline & $\begin{array}{l}\text { Competition in the } \\
\text { market }\end{array}$ & 0.0675 & 6 & 0.0652 & 6 & 0.0695 & 6 & 0.0787 & 5 \\
\hline & $\begin{array}{l}\text { Better cooperation } \\
\text { between cooperatives } \\
\text { and public forestry } \\
\text { service }\end{array}$ & 0.0506 & 10 & 0.0516 & 10 & 0.0489 & 11 & 0.0453 & 10 \\
\hline $\mathrm{O}$ & $\begin{array}{l}\text { Providing funds for } \\
\text { management }\end{array}$ & 0.0999 & 3 & 0.1019 & 3 & 0.1017 & 2 & 0.1033 & 2 \\
\hline & Extension of activities & 0.0827 & 4 & 0.0843 & 4 & 0.0782 & 4 & 0.0833 & 4 \\
\hline & $\begin{array}{l}\text { Adoption to market } \\
\text { conditions }\end{array}$ & 0.0491 & 11 & 0.0499 & 11 & 0.0501 & 10 & 0.0472 & 9 \\
\hline & $\begin{array}{l}\text { Non-cooperation } \\
\text { between owners }\end{array}$ & 0.1635 & 1 & 0.1660 & 1 & 0.1591 & 1 & 0.1775 & 1 \\
\hline $\mathrm{T}$ & $\begin{array}{l}\text { Promoting of cooperation } \\
\text { by Public Forestry } \\
\text { Service in other forms }\end{array}$ & 0.0602 & 8 & 0.0612 & 8 & 0.0670 & 7 & 0.0565 & 8 \\
\hline & $\begin{array}{l}\text { Strong competition in the } \\
\text { market }\end{array}$ & 0.0636 & 7 & 0.0646 & 7 & 0.0703 & 5 & 0.0614 & 7 \\
\hline
\end{tabular}

Table 13: Global priorities and ranks for SWOT factors, obtained by group AHP methods.

The A'WOT analysis, carried out on the surveys' data generates the importance of the SWOT factors and groups, thus giving the information which of them are important for the most suitable management of private forests, according to the set goals. The most important factor was threat Non-cooperation between owners with priority ranging from 0.16 to 0.18 . The second and the third place went to the weakness Focus on local markets and the opportunity Providing funds for management. The rankings of the factors were similar for all methods.

The results of A'WOT method can also be employed for the generation of management strategies and for the process under consideration. Based on the analysis carried out according to A'WOT the most important aspect is that cooperatives minimize weaknesses to avoid threats. This is the reason why we 
decided to use a defensive approach to strategic planning. This approach represents a combination of strategic guidance: entering of cooperatives in the global market, which would force cooperatives to start cooperating and meanwhile enable them to create a more complex cooperative business system cooperatives will have a greater influence on market conditions and have a better competitive position. This will ensure a better market position for the members, which would discourage them from disloyalty. By minimizing the weaknesses the cooperatives will easily avoid threats like non-cooperation between owners and strong competition in the market. If cooperatives strengthen their position they will also be more attractive for forest owners and the promotion of cooperation by Public Forestry Service and other forms will have no influence on their performance.

The FP indexes of the group priorities in the Case study evaluated our proposed WGMDEA model as equally acceptable as the WGMM and in most cases better than the DEAW\&C and DEA-WDGD methods. Although similar final rankings of the SWOT factors indicate that the presented group AHP methods do not differ much on the real data. The most important advantage of the proposed WGMDEA model compared to the DEAW\&C and DEA-WDGD methods is in its regularity regarding the reciprocal property, and in its simplicity when compared to the WGMM.

\section{DISCUSSION AND CONCLUSION}

The comparison of the multiple criteria group decision making methods used within the AHP discussed in the paper shows that there are differences in the results achieved by various group methods that we have dealt with. In the paper we proved that these differences are not always the consequence of the natural differences between the methods but that the DEAW\&C and the DEA-WDGD methods have some drawbacks - they violate the reciprocal property, which is one of the required properties in the AHP model, because they use the arithmetic mean instead of the geometric mean. To avoid these drawbacks we suggested the WGMDEA method. The examples and the case study demonstrated that it provides similar results as the well known WGMM for the eigenvector 
prioritization procedure. Its great benefit is its formulation as an LP model. An LP model is much easier to solve than the eigenvector method. Further research should evaluate the differences in the results between the WGMDEA and WGMM in detail and should compare more group AHP methods, not only those that are based on DEA.

\section{References}

Aczel J, Alsina C (1986) On synthesis of judgments. Socio Econ Plan Sci 20:333-339

Aczel J, Saaty T (1983) Procedures for synthesizing ratio judgments. J Math Psychol 27:93-102

Ananda J, Herath G (2008) Multi-attribute preference modelling and regional land-use planning. Ecol Econ 65:325-335

Bryson N, Joseph A (1999) Generating consensus priority point vectors: a logarithmic goal programming approach. Comp Oper Res 26:637-643

Charnes A, Cooper WW, Rhodes E (1978) Measuring the efficiency of decision making units. Eur J Oper Res 2:429-444

Cho YG, Cho KT (2008) A loss function approach to group preference aggregation in the AHP. Comp Oper Res 35:884-892

Choo EU, Wedley WC (2004) A common framework for deriving preference values from pairwise comparison matrices. Comp Oper Res 31:893-908

Duke JM, Aull-Hyde R (2002) Identifying public preferences for land preservation using the analytic hierarchy process. Ecol Econ 42:131-145

Escobar MT, Moreno-Jimenez JM (2007) Aggregation of individual preference structures in AHPgroup decision making. Group Decis Negot 16:287-301

Forman E, Peniwati K (1998) Aggregating individual judgements and priorities with the Analytic Hierarchy Process. Eur J Oper Res 108:165-169

Hosseinian SS, Navidi H, Hajfathaliha A (2009) A new method based on data envelopment analysis to derive weight vector in the group analytic hierarchy process. J Appl Sci 18:33433349

Korpela J, Tuominen M (1997) Inventory forecasting with a multiple criteria decision tool. Int J Prod Econ 45:159-168.

Kurttila M, Pesonen M, Kangas J, Kajanus M (2000) Utilizing the analytic hierarchy process (AHP) in SWOT analysis -- a hybrid method and its application to a forest-certification case. Forest Policy and Economics 1:41-52.

Liberatore MJ, Nydick RL (1997) Group decision making in higher education using the analytic hierarchy process. Res High Educ 38:593-614

Mikhailov L (2004) Group prioritization in the AHP by fuzzy preference programming method. Comp Oper Res 31:293-301 
Moreno-Jimenez JM, Aguaron J, Escobar MT (2008) The core of consistency in AHP-Group

Decision Making. Group Decis Negot 17:249-265

Peniwati K (2007) Criteria for evaluating group decision-making methods. Math Comp Mod 46:935-47

Pezdevšek Malovrh Š, Krč J, (2006) Evaluation of the influence of institutional subjects on private forest management in Slovenia. Formec 2006: proceedings, 258-265

Ramanathan R, Ganesh LS (1994) Group preference aggregation methods employed in AHP: an evaluation and intrinsic process for deriving members’ weightages. Eur J Oper Res 79:249265.

Ramanathan R (2006) Data envelopment analysis for weight derivation and aggregation in the analytic hierarchy process. Comp Oper Res 33:1289-1307

Saaty TL (1980) Multicriteria Decision Making: The Analytic Hierarchy Process. McGraw-Hill, New York

Saaty TL (2001) Fundamentals of Decision Making and Priority Theory with the Analytic Hierarchy Process. RWS Publications, Pittsburgh

Saaty TL, Vargas LG (2007) Dispersion of group judgements. Math Comput Model 46:918 - 925

Srdjevic B (2007) Linking analytic hierarchy process and social choice methods to support group decision-making in water management. Decis Support Syst 42:2261-2273

Sun L, Greenberg BS (2006) Multicriteria Group Decision Making: Optimal Priority Synthesis from Pairwise Comparisons. J Optimiz Theory App 130:317-338

Wang YM, Chin KS (2009) A new data envelopment analysis method for priority determination and group decision making in the analytic hierarchy process. Eur J Oper Res 195:239-250

Zahedi F (1986) A simulation study of estimation methods in the analytic hierarchy process. Socio Econ Plan Sci 20:347-354

Zahir S (1999) Clusters in a group: Decision making in the vector space formulation of the analytic hierarchy process. Eur J Oper Res 112:620-634 